\title{
Keratinization Induction
}

National Cancer Institute

\section{Source}

National Cancer Institute. Keratinization Induction. NCI Thesaurus. Code C40823.

Keratinization Induction consists of initiation of activities involved in proliferation and

maturation of tightly bound keratinocytes transiting passively from the basal to the corneal layer of the skin. 